\title{
КОНЦЕПЦИЯ РЕЧЕВЫХ АКТОВ ДЖ. ОСТИНА КАК ИСТОЧНИК ТЕОРИИ ДИСКУРСА Ю. ХАБЕРМАСА
}

\section{И.А. Яременко}

Актуальность данной статьи обусловлена тем, что коммуникативная концепция Ю. Хабермаса относится, на наш взгляд, к одному из наиболее влиятельных и перспективных течений в современной практической философии - коммуникативной философии. Его теория коммуникативного действия представляет собой междисциплинарный синтез- сотрудничество философии с другими реконструктивными науками: лингвистикой, психологией, социологией. Сотрудничество, в котором ни одна из дисциплин не занимает привелегированное положение по отношению друг к другу. Поэтому особый интерес у немецкого философа вызывают исследования представителей новых, современных ему направлений философии - лингвистической философии и философии языка, к которым, прежде всего, относятся известные философы Джон Остин и Джон Серль. В связи с этим целью данной статьи является рассмотрение лингвистической теории Дж. Остина как одного из возможньх теоретических источников теории дискурса Ю. Хабермаса. Для достижения названой цели в статье анализируются понятия «перформативное и констативное высказывание» в теории Дж. Остина, его концепция речевого акта и типов речевых актов, классификация им перформативных глаголов.

В основе концепции Дж. Остина лежит идея аналитической философии о том, что одной из главных задач философского исследования является прояснение выражений обыденного языка. Другая проблема, стоявшая в центре внимания исследователя, - это возможность осо- 
знания «чужих сознаний» и его отражение в языке. Дж. Остин надеялся, что в результате его деятельности возникнет новая дисциплина, являющаяся симбиозом философии и лингвистики, - «лингвистическая феноменология», в границах которой логические явления предлагалось рассматривать без отвлечения от их основного содержания. По его мнению, такая дисциплина должна изучать способы употребления естественного языка: если в качестве элементарного предмета «лингвистической феноменологии» выступает «утверждение», то соответствующим предметом логики является «предложение».

Согласно его мысли, каждое «утверждение», произносимое кем-то, есть акт производства, который представляет собой своеобразное историческое событие, а именно - высказывание конкретным говорящим определенного «предложения», относимого к слушателю с указанием на конкретное положение дел или же какую-то историческую ситуацию. Повседневное употребление слов «истинно» или «ложно» соответствует, по мнению Дж. Остина, утверждению, а не предложению. Предложение не может считаться истинным или ложным, поскольку оно всякий раз сопоставляется типам событий. Утверждение же соответствует, с известной долей неопределенности, исторически меняющимся событиям.

Важное место в работах этого философа занимает исследование понятий перформативного и констатирующего высказываний, которые он рассматривает как очередной шаг в развитии логических представлений о границе между осмысленными и бессмысленными высказываниями. Термин «перформативное предложение» или «перформатив» употребляется им применительно к различным родственным конструкциям примерно так же, как, например, употребляется термин «императив». Это название производно от «perform» (представлять, осуществлять, исполнять), оно указывает на то, что произнесение высказывания означает совершение действия, а не простое произнесение слов. Под «констативными предложениями» или «констативами» Дж. Остин понимал высказывание, выражающее определенное положение дел в мире. Критерием оценки перформативов является успешность или неуспешность, критерием ощенки констативов истинность или ложность.

Развивая понятие успешности перформативного предложения, Дж. Остин формулирует следующие правила его успешного осуществления $[1$, с. $35-46]$ :

- Должна существовать принятая конвенциональная процедура, 
имеющая определенные конвенциональные результаты, включающая употребление определенных слов определенными лицами при определенньх обстоятельствах.

- Конкретные люди в конкретных обстоятельствах в определенном случае должны соответствовать обращению именно к данной конкретной процедуре.

- Процедура должна выполняться всеми участниками правильно.

- Процедура должна выполняться всеми участниками полностью.

- Если процедура предполагает у участников определенные мысли, чувства и установки или она направлена на возбуждение у участников поведения определенного типа, то лицо, учавствующее в процедуре и вызывающее ее к жизни, обязано реально испытать эти мысли, чувства или установки и другие участники готовы также вести себя соответствующим образом.

Дж. Остин также описывает условия истинности констативного утверждения. По его мнению, предложение является истинным не в том случае, когда оно соответствует фактам, а когда имеется два ряда конвенций: «Дескриптивные конвенции ставят слова (предложения) в соответствие с типами ситуаций, вещей, событий и т. д., которые могут быть обнаружены в мире. Демонстративные конвенции ставят в соответствие слова (предложения) с историческими ситуациями и т. д., которые могут быть обнаружены в мире» [2, с. 295]. Итак, об утверждении говорится, что оно является истинным, когда историческое положение дел, соответствующее ему с помощью демонстративных конвенций, относится к тому типу, которому с помощью дескриптивных конвенций соответствует предложение, использованное для производства утверждения.

В дальнейшем эти идеи были преобразованы в теорию речевых актов. Речевым актом Дж. Остин называет «такой процесс общения определенных индивидов, в котором помимо высказывания осмысленных выражений имеет место интерактивное воздействие коммуникантов друг на друга» [1, с. 86]. По его мнению, совершить речевой акт, значит:

- совершить действие употребления определенных звуков («фонетическое действие»); 
- совершить действие употребления определенных вокабул или слов, то есть звуков определенного типа, принадлежащих определенному словарю, определенной конструкции и определенной грамматике с определенной интонацией. Это действие Дж. Остин называет фатическим, а употребление, посредством которого данное действие совершается, - «фемой»;

- совершить действие использования этой фемы или ее составляющих с определенным смыслом и определенной «референцией» (что вместе составляет значение). Это действие Дж. Остин называет «ретическим», а употребление, посредством которого это действие совершается, «ремой» [1, с.82]. Фема является единицей языка, она бессмысленна и не обладает значением. Рема же является единицей речи, но ее недостаток состоит в том, что она может быть неясной, или пустой, или расплывчатой.

Единый речевой акт представляется Дж. Остину трехуровневым образованием. Речевой акт в отношении к используемым в его ходе языковым средствам выступает как локутивный акт; в отношении к манифестируемой цели и ряду условий ее осуществления - как иллокутивный акт; в отношении к свонм результатам - как перлокутивный акт. Он дает следующее определение речевых актов:

Мы совершаем локутивное действие, которое приблизительно эквивалентно употреблению определенного предложения с определенным смыслом и определенной референщией, тто опятьтаки приблизительно эквивалентно «значению» в традиционном смысле .. . Мы также можем совершать иллокутивные действия, такие как информирование, приказ, предостережение, то есть употребления, которые имеют определенную конвенцинальную силу ... Мы можем совершать также перлокутивные действия то, что мы привносим или достигаем посредством говорения чего-либо, например, убеждение, принуждение, устрашение [1, c. 99].

Таким образом, теория речевьх актов Дж. Остина основывается на различении локутивных, иллокутивных и перлокутивных актов. Различие между ними состоит в том, что локутивные акты-это речевые высказывания, в которых нечто просто сообщается. Локутивный акт выражает положение дел, он строится в отношении к используемым в ходе его осуществления языковым средствам. Локутивные акты изучаются семантикой. Перлокутивные акты - это речевые акты, при 
помощи которых говорящий нацелен на то, чтобы вызвать эффект у слушателя. Если он говорит нечто в данной ситуации, то из этого следует что-то. Посредством перлокутивных актов происходит интеграция речевых действий в структуру стратегических действий; таким образом, осуществляется вмешательство и интервенция в мир, достигается эффект в силу того, что нечто делается через то, что говорится. С этой точки зрения перлокутивнье действия описываются и характеризуются в отношении к своим результатам; их изучает риторика.

Особое место в теории Дж. Остина занимают так называемые иллокутивные акты. По его определению, «иллокутивный акт - это действие, которое осушествляется, когда выражается некоторое положение дел, при этом происходит полагание модуса высказывания, к примеру, признания, приказа, обещания, предупреждения, то есть это как бы двойной акт, где в одном месте определяется сам характер этого полагания, а в другом за счет пропозициональной структуры нечто сообщается $[1$, с. 88$]$.

Ю. Хабермас так описывает речевые акты типологии Дж. Остина: «Все три акта, которые различает Остин, можно кратко охарактеризовать следующим образом: что-то говорить; действовать, говоря чтото; влиять на что-то посредством своего действия, возникающего в процессе говорения» [3, с.389]. Каждое утвердительное предложение, которое кто-либо высказывает, направлено на слушателя. Вследствие этого оно имеет интерактивную взаимосвязь, несущую нормативную базу, которая выполняется или нарушается в процессе коммуникативного действия. Каждое утвердительное предложение имеет пропозициональную часть, в которой содержится высказывание, выражающее претензию на истинность. Кроме того, оно имеет иллокутивную часть, которая наделяет его интерактивностью. По определению Хабермаса, «иллокутивный акт определяет намерение употребления пропозиционального содержания» $[4$, с. 406]. Если, к примеру, пропозициональной составной частью высказывания является «мой завтрашний приход», то она может быть переплетена с различными иллокутивными актами: в качестве простого сообщения (я сообщаю тебе, что я приду завтра); в качестве заверения (ты можешь быть совершенно уверен, что я приду завтра); в качестве экспрессии (я надеюсь, что я приду завтра); в качестве обещания (я обещаю тебе, что я приду завтра). Пропозициональное содержание предложения всегда одно и то же: я приду завтра. Однако каждый из приведенных примеров имеет различное намерение. «Для одного и того же высказывания имеется как угодно много зависящих от контекста целей употребления» [5, с. 357]. 
В этом заключается основная особенность иллокутивных актов, которые, по мнению Ю.Хабермаса, имеют первостепенное значение для теории дискурса. В них расходятся структура оценки, которая закладывается извне, и эффект события, который должен произойти изнутри. Другой участник коммуникативного действия (или несколько коммуникантов) должен понять сказанное. Именно здесь возникает расхождение их необходимой реакции и понимания и цели данного речевого акта. Эта реакция не предрешена и не определена. Эффект понимания не снят и не предзадан автоматически. Именно с этой непредзаданностью Ю. Хабермас связывает огромные возможности коммуникативных действий, в отличие от стратегических действий, основанных на калькуляции выгод и вычисляемых перемещениях по шкале: цель, средство, результат. Иллокутивные акты рассматриваются Ю. Хабермасом с точки зрения понимания содержания высказывания, внутренних для речевых актов подтверждений и последующих взаимодействий, возможностей установить связь. Условием этого является понимание или схватывание заложенной в речевых актах претензии на значимость. Это тоже очень важное различение Ю. Хабермаса, так как он кроме значений выделяет значимость, которая должна быть схвачена оппонентом.

Значение теории речевых актов обусловлено ведущей проблемой понимания выражений естественного языка, что связано со спецификой понятия иллокутивного акта - высказывания, обладающего определенной силой: просьба, угроза, извинение и так далее. На разном этапе создания теории речевых актов возникали проблемы обеспечения иллокутивного взаимодействия (обеспечение понимания слушающим того, что имел в виду говорящий), знания интенционационального содержания, сопровождающего лингвистическую форму его воплощения. Локутивный акт включает в себя фонетический, фатический и ретический акты и соотносится Дж. Остином с констативным высказыванием. Иллокутивные акты соответствуют перформативным предложениям.

Ю. Хабермас подчеркивает значение исследований Дж. Остина для развития универсальной прагматики: «Остин отходит от онтологии, которая направлена исключительно на объективный мир в качестве совокупности существующих обстоятельств и имеет целью выделение ассерторических (утвердительных, констатирующих) предложений. Своим понятием иллокутивного акта он открывает языковому анализу целый спектр речи» [4, с. 362]. Дж. Остин стремится выявить то, как люди структурируют определенную ситуацию и как различные 
способы употреблений естественного языка характеризуют различные ситуации в мире. Он ставит задачу противопоставления слов по отношению к миру, в результате чего можно обнаружить неадекватность и произвольность используемых слов. Дж. Остин стремится смотреть не только на слова, но и на реалии, для разговора о которых мы используем данные слова, и изучать то, как изменение факторов в ситуации влияет на произнесение выражений естественного языка.

Таким образом, на основании проведенного исследования можно сделать вывод о том, что теория речевых актов Дж. Остина, характеризующаяся одновременным развитием принципов субъективности и рациональности, является одним из теоретических источников коммуникативной концепции Ю. Хабермаса. Иллокутивные акты классификации Дж. Остина Хабермас кладет в основу коммуникативного действия, выделяя значимость высказывания, понимание которого выступает необходимым условием в достижении согласия в коммуникативном действии.

\section{1 Литература}

[1] Остии Дюк. Как совершать действия при помощи слов // Избранное. Перевод с англ. Макеевой Л.Б., Руднева В.П. - М.: Идея Пресс, Дом интеллектуальной книги, 1989. - С. 13-136.

[2] Остин Дж. Истина // Избранное. Перевод с англ. Макеевой Л.Б., Руднева В.П. - М.: Идея Пресс, Дом интеллектуальной книги, 1989. - C. $290-307$.

[3] Habermas J. Theorie des kommunikativen Handeln. B.I. Handlungsrationalität und gesellschaftliche Rationalisierung Frankfurt: Suhrkamp Verlag, 1981.

[4] Habermas J. Vorstudien und Ergänzungen zur Theorie des kommunikativen Handelns - Frankfurt am Main: Suhrkamp Verlag, 1984.

[5] Habermas J. Entgegnung// Honneth A., Joas H. (Hg). Kommunikatives Handeln. Beiträge zu Jürgen Habermas' «Theorie des kommunikatives Handelns». - Frankfurt am Main: Suhrkamp Verlag, 1986. S. $327-406$. 